\section{Mag. Magda Zupančic}

Ministrstvo za delo, družino in socialne zadeve

\title{
MENTORSTVO - ZNANJE PRETEKLOSTI ZA IDEJE PRIHODNOSTI
}

\section{POVZETEK}

Mentorstvo je oblika prenosa znanja in izkušenj, ki v delovnem okolju pridobiva vedno večjo veljavo. Omogoča osvajanje novih znanj, iskalcem zaposlitve daje nova delovna mesta ter zmanjšuje neravnotežje med ponudbo in povpraševanjem na trgu dela. Vključuje več raznolikih aktivnosti, povezuje mlade in starejše sodelavce, izkušene in novozaposlene $v$ podjetju. Predvsem $v$ kriznih časih lahko pripomore $k$ hitrejšemu prehodu mladih iz izobraževanja/usposabljanja $v$ zaposlenost ter s tem $k$ nižji stopnji brezposelnosti mladih. Ob vzajemno odgovornem razvijanju mentorskih shem na podlagi izkušenj uspešnih držav, ki so mentorstvo že uvedle, lahko tudi v Sloveniji razvijemo svoj sistem prenosa znanja in izkušenj, s tem pripomoremo $k$ ohranjanju in nadgradnji obstoječega znanja in izkušenj v delovnem okolju ter dosežemo večjo vključenost $v$ trg dela.

Ključne besede: mentorstvo, krožno zaposlovanje, kompetence, prenos znanja

\section{MENTORING - THE KNOWLEDGE ACQUIRED FOR FUTURE IDEAS - ABSTRACT}

Mentoring is a tool which enables the transfer of knowledge: it is receiving more and more attention in work environments. Mentoring offers new knowledge and competences, new job opportunities to job seekers on the one hand, and reduces labour market imbalances in the demand and supply of professions on the other. Mentoring includes various forms of activities, connects younger and older employees, those experienced and the first job seekers. In the times of economic crisis, mentoring can enable a smoother transition of youth from education/training into the labour market, and might contribute to lower unemployment rates for young people. By respecting the responsibilities of all partners involved, Slovenia could develop its own system of knowledge transfer on the basis of the experiences of the successful countries which have already implemented mentoring schemes. This could help Slovenia broaden its existing stock of knowledge and experiences and improve its performance in the labour market.

Keywords: mentoring, job-rotation, competences, transfer of knowledge

UDK: 331.36

Negotove krizne gospodarske razmere v Sloveniji že nekaj časa negativno vplivajo na trg dela. Brezposelnost je visoka, možnosti za ustvarjanje novih delovnih mest ni veliko, velike težave pri vključevanju na trg dela med drugim občutijo predvsem mladi prvi iskalci zaposlitve, delno zaradi že omenjenih manjših potreb po delavcih, delno pa tudi zaradi neusklajenosti med ponudbo znanja mladih in potreb delodajalcev, ki v teh kriznih časih še zaposlujejo. Po drugi strani si starejši posamezniki na trgu dela želijo predajati znanje in izkušnje, pri tem pa imeti možnost fleksibilnejšega dela ob počasnejšem odhodu $\mathrm{s}$ trga dela.

\section{KAJ PRINAŠA MENTORSTVO V DELOVNEM PROCESU}

Mentorstvo je praktična oblika izmenjave znanj in izkušenj, ki v Evropi v zadnjem času 
pridobiva vedno večjo veljavo, dejansko pa lahko prinaša praktično izkušnjo pridobivanja in podajanja znanja med mladimi in starejšimi, med novozaposlenimi in tistimi, ki želijo svoje znanje in izkušnje prenesti na prihodnje rodove ali na sodelavce (tudi $\mathrm{v}$ neformalni obliki). V kriznih razmerah mentorstvo predvsem za mlade iskalce zaposlitve pomeni možnost mehkejšega in hitrejšega prehoda iz teoretičnega izobraževanja $\mathrm{v}$ praktičen delovni proces, drugim kategorijam iskalcev zaposlitve pa daje možnost približevanja povpraševanju delodajalcev po posameznih poklicnih profilih $\mathrm{v}$ obliki prekvalifikacije oziroma priučitve deficitarnih poklicev, ki so iskani pri delodajalcih, kar po drugi strani povečuje njihove zaposlitvene možnosti.

Poglejmo situacijo iz perspektive mladih. Od leta 2008 se je brezposelnost med mladimi $\mathrm{v}$ Uniji povečala za pet milijonov, $\mathrm{v}$ nekaterih državah Unije se že vsak drug mlad človek srečuje s problemom brezposelnosti. Tudi $\mathrm{v}$ Sloveniji se je položaj v zadnjih letih poslabšal, v letu 2011 je stopnja brezposelnosti mladih (od 15 do 24 let) znašala 15,7 odstotka (EU-27 21,4 odstotka). Od leta 2008 je brezposelnost med mladimi v Sloveniji narasla za 5,3 odstotne točke, dodatno narašča tudi brezposelnost diplomantov, poleg stagnacije v gospodarstvu tudi zaradi poklicne izbire, po kateri delodajalci ne povprašujejo.

Razmere pri starejših so drugačne, bolj specifične. Po eni strani starejši razpolagajo s tistimi znanji, po katerih delodajalci bolj povprašujejo (torej konkretna znanja), po drugi strani pa nimajo sistemskih možnosti, da bi svoje znanje in izkušnje prenašali na druge. Stopnja delovne aktivnosti starejših v Sloveniji je med najnižjimi v EU, v letu 2011 je v starostni kategoriji od 55 do 64 let še nadalje upadla na 29 odstotkov (EU-27 32 odstotkov). Demografska gibanja zahtevajo hitre ukrepe za reaktivacijo starejših na trgu dela, mentorstvo pa pri tem omogoča neposreden prenos znanja ob že omenjenem počasnejšem odhajanju s trga dela za starejše ter hitrejše prehajanje iz teoretičnega učenja $\mathrm{v}$ praktično delovne okolje za mlade oz. novozaposlene posameznike.

Mentorstvo $\mathrm{v}$ obliki mentorskih shem ter nadomeščanja na delovnem mestu in delitve delovnega mesta, ki lahko prinese medgeneracijski prenos znanja, je v Sloveniji novost, predvidena $\mathrm{v}$ novem Zakonu o urejanju trga dela, ki je začel veljati v začetku leta 2011.

V januarju 2011 je namreč začel veljati novi Zakon o urejanju trga dela, ki ga je ministrstvo za delo, družino in socialne zadeve (MDDSZ) pripravilo in sprejelo s ciljem prilagoditi se razmeram na trgu dela ter s tem povečati učinkovitost zaposlovanja.

Načrtuje se razvijanje novega programa »mentorske sheme«, ki bo namenjen prenosu delovnih izkušenj, znanj in veščin starejših zaposlenih na mlajše brezposelne oz. iskalce zaposlitve, po drugi strani pa bo podjetjem in njihovim zaposlenim omogočil sistematično uvajanje novozaposlenih $\mathrm{v}$ delovni proces. Tista podjetja, ki še niso izdelala načrta izvajanja mentorstva v okviru mentorskih shem, bodo $\mathrm{s}$ tem programom dobila dodatno spodbudo za to.

Z uvedbo mentorstva (mentorskih shem) sta konkretno povezani dve aktivnosti, in sicer nadomeščanje na delovnem mestu in delitev delovnega mesta, cilj aktivnosti pa je pridobivanje novih znanj in kompetenc ljudi, ki so zaposleni pri delodajalcih, ter povečevanje konkurenčnosti in prožnosti podjetij, ki usposabljajo svoje zaposlene delavce. Nadomeščanje na delovnem mestu se bo predvidoma izvajalo kot subvencioniranje popolne 
nadomestitve zaposlenega $\mathrm{z}$ brezposelno osebo, pri tem da odsotni delavec $\mathrm{v}$ času odsotnosti zaradi izobraževanja/usposabljanja prejema plačo, brezposelno osebo, ki se začasno zaposli, pa plačuje Zavod RS za zaposlovanje (torej ni obveznosti in bremen za delodajalca). Delitev delovnega mesta pa se izvaja s subvencioniranjem delne nadomestitve zaposlenega $\mathrm{z}$ brezposelno osebo.

Kaj v praksi pomenijo omenjeni ukrepi? Mentorske sheme kot ukrep so v praksi zasnovane kot program za izmenjavo in prenos znanja, spretnosti, izkušenj med zaposlenimi. Poseben poudarek je namenjen medgeneracijskemu prenosu znanja, kompetenc in informacij. V tem okviru so zastavljene aktivnosti, ki lahko uvajajo inovativne pristope prenosa znanj in pospeševanja razvoja novih zaposlitvenih možnosti, kamor med drugim sodijo mentorske in inštruktorske sheme, t. i. coaching, medgeneracijske mentorske sheme ipd.

Ukrep mentorske sheme predvideva za novozaposlene osebe sistematično uvajanje $\mathrm{v}$ veščine in znanja, ki so nujno potrebni za hitro in uspešno vključitev novozaposlenega $\mathrm{v}$ delovni proces $\mathrm{v}$ podjetjih, da lahko čim prej začne samostojno delati. Pri tem je pomembno, da naj bi mentorji po vnaprej izdelanem programu novozaposlene ne le uvajali v delovni proces, temveč jim tudi predstavili podjetje, splošno organizacijo, način dela ter kulturo podjetja.

Primer za takšen prenos znanj je podjetje Paloma. Aprila letos je ministrstvo za delo, družino in socialne zadeve $\mathrm{v}$ okviru programov EU ter ob prijaznem sodelovanju Centra Evropa organiziralo strokovni posvet »Medgeneracijski prenos znanja - družbeno odgovorno spodbujanje aktivnega staranja «. Prvi posvet/okroglo mizo smo namenili izzivu aktivnega staranja, prenosa znanja in s tem družbene odgovornosti. Eden od namenov posveta pa je bil ravno promocija mentorstva in prenosa znanj $\mathrm{v}$ delovno okolje.

Kot primer dobre prakse razvijanja mentorstva je ministrstvo povabilo podjetje Paloma $\mathrm{k}$ predstavitvi svojega modela mentorskih shem. Podjetje $\mathrm{z}$ izdelanim sistemom družbene odgovornosti se po besedah predsednika uprave zaveda pomena prenosa znanja in izkušenj. Omenjeno zavezo so odločeni razvijati v smislu mentorstva kot tudi vzpostavitve baze znanja predvsem na področju proizvodnje in predelave papirja kot ključnega proizvodnega izdelka. Zaradi odprave izobraževalnih programov za profil, ki je v podjetju ključen, so se odločili za ukrep s pomočjo medgeneracijskega prenosa izkušenj in znanj prek mentorstva starejših sodelavcev, dodatno pa želijo z nadomeščanjem na zahtevnejših delovnih mestih usposobiti nove zaposlene, ki bodo nadomestili odhajajočo starejšo generacijo.

Pri tem je predsednik uprave Palome poudaril pomen dvostranske izmenjave izkušenj, tako »da bodo starejši učili mlajše o sistemu dela in vrednotah v podjetju, mlajši pa bodo starejše uvajali $v$ nove tehnologije in jih seznanjali z novostmi na področju stroke«. Dodaten pomen pa sta mentorstvo in pozitiven odnos do izkušenj starejših v podjetju pridobila s pristopom $\mathrm{k}$ uresničitvi ideje svetovno znanega izumitelja Petra Florjančiča. Ta je letos pri 93 letih starosti Palomi predložil svojo inovacijo serviete, ki je uspešno prestala razvojno pot in postala tržni izdelek.

Nadomeščanje na delovnem mestu vključuje razvijanje in nadgrajevanje profesionalnih 
veščin zaposlenih $\mathrm{v}$ podjetjih ter sočasno usposabljanje brezposelnih, ki nadomestijo zaposlene $\mathrm{v}$ podjetju $\mathrm{v}$ času njihove odsotnosti. Temeljni namen predvidenega ukrepa je zagotoviti podjetjem nepretrgan delovni proces $\mathrm{v}$ času, ko zaposleni zaradi usposabljanja ali izobraževanja začasno zapustijo svoje delovno mesto. Zaposlenega, ki se izobražuje ali usposablja, nadomesti brezposelna oseba, ki je ustrezno usposobljena ali v fazi pridobivanja ustreznih veščin, kar omogoča takojšno vključitev v delovni proces podjetja. S takim pristopom ostane število zaposlenih $\mathrm{v}$ podjetju na taki ravni, da ne prihaja do izpada delovnega procesa, kar podjetju omogoča nemoteno in konkurenčno delovanje.

Nadomeščanje na delovnem mestu (tudi job rotation, krožno zaposlovanje) zahteva seveda ustrezne razmere, ki omogočajo izvedbo ukrepa. Predvsem v manjših podjetjih je potrebno bistveno večje usklajevanje delovnega procesa, saj je bistveno teže nadomestiti odsotnost posameznika, tudi če gre za odsotnost zaradi nadgradnje znanja, ki je ključna za konkurenčnost in produktivnost podjetja. Ukrep zahteva tudi ustrezno urejeno financiranje, strategijo in odgovornost udeležencev, predvsem pa morata biti vnaprej določeni struktura in organizacija aktivnosti nadomeščanja na delovnem mestu. Zaradi tega je za učinkovitost ukrepa pomembno usklajeno delovanje »trikotnika«, ki v najbolj idealnem smislu pomeni usklajenost Zavoda RS za zaposlovanje z bazo razpoloŽljivih in primernih iskalcev dela, izobraževalnih ustanov in delodajalcev.

Udeleženci študijskega obiska v Aalborgu pa smo si v okviru mednarodnega projekta pred časom ogledali tudi primer uspešnega sistema delitve delovnega mesta na Danskem. Na Danskem je delitev delovnega mesta pomemben ukrep aktivne politike zaposlovanja, pri tem imajo delodajalci $\mathrm{v}$ zasebnem ali javnem sektorju pravico, da uporabijo shemo delitve delovnega mesta med začasno odsotnostjo zaposlene osebe. Če delodajalci privolijo $\mathrm{v}$ odsotnost zaposlenega (večinoma zaradi usposabljanja), delodajalci določijo obliko usposabljanja in jo finančno podprejo, po drugi strani pa so upravičeni do finančnega nadomestila za zamenjavo odstotnega zaposlenega (plačo nadomestnega delavca subvencionira agencija za delo). Odsotnega delavca lahko tako med začasno odsotnostjo nadomesti oseba, ki je brezposelna vsaj tri mesece in bo začasno zaposlena vsaj deset ur na teden ter za obdobje največ 12 mesecev. Nadomestni delavec je plačan po kolektivni pogodbi po običajnih pogojih zaposlitve. Pomembno je pripomniti, da je administracija ukrepa izredno poenostavljena, delodajalec izpolni zgolj en obrazec za sodelovanje $\mathrm{v}$ ukrepu ter dodaten obrazec za izplačilo, agencija povrne 100 odstotkov stroškov plače, kar nedvomno poveča privlačnost ukrepa za delodajalce.

Delitev delovnega mesta ponuja okvir za novo obliko delitve delovnega mesta med starejšim delavcem in mlado brezposelno osebo skozi mentorsko shemo. Na podlagi novega Zakona o urejanju trga dela bo predvsem ta ukrep predvidoma pripomogel $\mathrm{k}$ večjemu vlaganju v človeški kapital in kompetence brezposelnih oseb, kar naj bi brezposelnim omogočilo večjo zaposljivost na trgu dela. Tako bo ta ukrep predvidoma pripomogel $\mathrm{k}$ zmanjševanju brezposelnosti med mladimi ter omogočil krajše, a fleksibilnejše delo starejših ob prenosu delovnih izkušenj in znanja. Vsekakor je treba poudariti, da se predvsem pri delitvi delovnega mesta lahko srečamo $\mathrm{s}$ težavami financiranja stroškov (povrnitev stroškov prevozov za dve osebi ...) kot tudi s težavami pri usklajevanju dela. 


\section{MENTORSTVO IN VNOVIČNI VZPON MODELA PRIPRAVNIŠTVA - ODZIV EVROPSKE UINIJE}

Kakšno vlogo ima mentorstvo za mlade in starejše udeležence ukrepa $v$ evropskem okolju? Neugoden položaj mladih na trgu dela je bil razlog za konkretnejše ukrepe za uspešnejše vključevanje mladih na trg dela, tudi v sklopu uveljavljanja t. i. garancije za mlade oz. »Youth Guarantee« v letu 2010, in sicer kot predlog znotraj pobude $»$ Mladi in mobilnost $\ll .{ }^{1}$ Omenjena pobuda zajema oblikovanje celostnih politik, ki se bodo osredotočile na hitrejši prehod iz izobraževanja na trg dela, vključno s sistemi pripravništva in karierne orientacije.

Že v letu 2010 je Evropski parlament potrdil pobudo o večji vlogi pripravništva z željo po spremljanju ustaljenih praks pripravništva po državah članicah pod naslovom »Spodbujanje dostopa mladih na trg dela z okrepitvijo statusa med pripravništvom, delovno prakso in vajeništvom ${ }^{2}{ }^{2}$

Ob slabšanju položaja mladih na trgu dela je Evropska komisija v letu 2011 predložila dodatno pobudo »Priložnosti za mlade $\ll,{ }^{3}$ kjer je poudarila podporo intenzivnejšemu uvajanju pripravništva, tudi $\mathrm{z}$ večjim finančnim prispevkom evropskih sredstev.

V juniju 2011 so sklepi Sveta vključevali zavezo držav članic za izboljšanje možnosti za kakovostno opravljanje pripravništva, tudi s pomočjo t. i. »kakovostnega okvira pripravnišstva« ${ }^{4}$

Omenjena zaveza je še nadalje podkrepljena s sporočilom Evropske komisije $» \mathrm{~K}$ okrevanju s številnimi novimi delovnimi mesti $\ll,{ }^{5} \mathrm{ki}$ poudarja pomen skupnega priznavanja okvira za kakovost pripravništva $\mathrm{v}$ obliki priporočila Sveta še v letu 2012.
Sočasno je Evropski mladinski forum (European Youth Forum) predstavil predlog Listine o evropskem pripravnišstvu (European Internship Charter), ${ }^{6}$ ki sloni na ugotovitvah posvetovanja med mladimi. Listina poudarja zmanjšano kakovost in obseg znanja, pridobljenega med opravljanjem pripravništva, z zahtevo po resnejšemu razmisleku o dvigovanju kakovosti pripravništva (strokovno mentorstvo).

$\mathrm{Z}$ vidika starejših je razveseljivo, da je bilo letošnje leto razglašeno za evropsko leto aktivnega staranja in medgeneracijske solidarnosti. Tako evropsko leto aktivnega staranja in medgeneracijske solidarnosti 2012 pomeni še en kamenček v mozaiku kontinuiranih dejavnosti, s katerimi želijo Evropska unija in države članice spodbujati uresničenje vizije starosti prijazne Evrope na temeljih družbe vseh starosti, pri čemer velja dati poudarek tako aktivnemu staranju kot medgeneracijski solidarnosti ter sodelovanju in tkanju vezi med različnimi generacijami. Dodatno se je Unija zavezala k sprejetju t. i. načel aktivnega staranja do konca leta 2012, kjer ima pomembno vlogo večje ozaveščanje o pomenu prenosa znanja in izkušenj za družbo, podjetja in posameznike. Pri tem je pomemben prenos znanja v smislu kapitalizacije znanj in izkušenj starejših v obliki mentorstva in drugih generacijsko raznovrstnih načinov prenosa znanj in izkušenj.

\section{Primer Avstrije: pripravništvo Supra-Company}

Usposabljanje »Supra-Company« kot del »Zaposlitvenega paketa mladih 2008 « je ukrep zagotavljanja pripravništva za mlade, ki jim ni uspelo najti pripravništva po dokončanju obveznega šolanja. Sodi v 
reformo iz leta 2008, ko je bil ukrep uvrščen v celostni dualni sistem, ki omogoča zaključek usposabljanja s standardnim certificiranjem.

Pripravništvo »Supra-Company « se vedno intenzivneje uporablja pri aktiviranju osipnikov oz. »starejših mladih oseb « v Avstriji kot tudi pri drugih ranljivih kategorijah posameznikov. Dogovor o izvajanju se sprejme v sodelovanju med zvezno vlado in socialnimi partnerji, število udeležencev $\mathrm{v}$ ukrepu pa se nenehno povečuje.

\section{Primer Portugalske: strokovno pripravništvo za mlade}

Program se osredotoča na vključevanje mladih na trg dela, in sicer ob nadgradnji pridobljenega teoretičnega znanja $\mathrm{v}$ delovnem okolju v obdobju največ devet mesecev. Pripravništvo omogoča prvi stik $\mathrm{s}$ trgom dela in po drugi strani pomaga podjetjem, predvsem malim in srednjim, da se zavejo pomena novih znanj in kompetenc, ki jih mladi lahko prinesejo $\mathrm{v}$ delovno okolje.

Program namreč ni namenjen zgolj večji zaposljivosti, temveč tudi vnosu inovativnosti v podjetja. Uspeh navedenega ukrepa (70-odstotni prehod $\mathrm{v}$ zaposlitev) je vodil v vključitev ukrepa med najpomembnejše instrumente aktivne politike zaposlovanja na Portugalskem v letih 2009 in 2010.

\section{Primer Cipra: shema zaposlovanja in usposabljanja visokoizobraženih oseb}

Gre za pobudo, usmerjeno v vključevanje visokokvalificiranih mladih oseb na trg dela s pomočjo praktične izkušnje dela $\mathrm{v}$ podjetju za obdobje največ 12 mesecev. Program ponuja mladim prvi stik s trgom dela, podjetjem, predvsem malim in srednjim, pa omogoča pridobitev novega znanja in svežih idej.

Program dejansko sodi med ukrepe aktivne politike zaposlovanja $\mathrm{v}$ sodelovanju z nacionalno agencijo za razvoj človeških virov (HRDA) in ministrstvom za delo in je bil prvič izpeljan v letu 2009. Pri tem je zanimiv položaj agencije HRDS, saj gre za tripartitno ustanovo, ki se financira $\mathrm{z}$ dajatvami delodajalcev (in zaposlenih) $\mathrm{v}$ zasebnih in deloma javnih podjetjih. Raznovrstna usposabljanja, ki jih ponuja agencija, so namenjena podjetjem in posameznikom ter se prilagajajo zahtevam trga dela in potrebnim nadgradnjam kompetenc za večjo konkurenčnost na trgu dela.

Program omogoča individualiziran akcijski načrt usposabljanja $\mathrm{z}$ odgovornim pristopom mentorja in se za udeležence pogosto konča s sklenitvijo delovnega razmerja v podjetju usposabljanja. Zastavljen je pregledno, brez zahtevnih administrativnih procedur, prilagaja se strukturi in velikosti podjetij.

Delodajalci čutijo odgovornost do prenosa znanja, s tem spoznavajo nove potencialne sodelavce, pomembno vlogo pri tem pa ima verjetno tudi finančna dajatev agenciji, ki je podlaga za večjo zavezo vključevanju v program usposabljanja.

Vse te programe $\mathrm{v}$ omenjenih treh državah povezujejo zavzetost za usmerjeno vlaganje $v$ znanje mladih ljudi, odgovorno predajanje znanja od mentorjev na mlade ter enostavnost postopkov. 


\section{ZAKLJUČEK}

Kaj nam lahko da mentorstvo? Nedvomno gre za že preverjeno prakso prenosa znanja in podajanja izkušenj v delovnem okolju. Omogoča povezovanje mladih in starejših, izkušenih in novozaposlenih posameznikov Mentorstvo je že
preverjena pra-
ksa prenosa zna-
nja in izkušenj v
delovnem okolju ter ob tem prenos tistega znanja in izkušenj, ki so se na trgu dela izkazali za potrebne in po katerih obstaja povpraševanje. Predvsem pripravništvo kot del mentorske sheme mora vključevati elemente zagotavljanja kakovosti in zavezo, po kateri bo pripravništvo vodilo do večje zaposljivosti in znanja ter ne bo postalo zgolj možnost za izkoriščanje poceni delovne sile brez kasnejšega prehoda $v$ trajnejšo zaposlitev ter razvoja kompetenc.

Slovenija ima nizko stopnjo delovne aktivnosti starejših, odnos družbe do starejšega sodelavca še zmeraj ni ustrezen za ploden medgeneracijski prenos in izmenjavo znanja ter izkušenj. $\mathrm{Ob}$ evropskem letu aktivnega staranja in medgeneracijske solidarnosti 2012 bodo zato za nas »načela aktivnega staranja « zelo pomembna, slednjim pa bodo morale več pozornosti nameniti vse države članice.

Kot pri vsakem ukrepu se tudi v okviru mentorstva postavlja vprašanje, kaj so prednosti in slabosti mentorstva. Vsekakor lahko pri medgeneracijskem prenosu znanja in izkušenj kot prednost vzpostavimo hitrejši prehod iz izobraževanja na trg dela $\mathrm{v}$ okviru tistega delovnega procesa, po katerem delodajalci dejansko povprašujejo. Omogoča praktičen prenos znanja in izkušenj, pridobitev prvih delovnih izkušenj ter povečuje možnost prehoda v redno zaposlitev. Ob mentorstvu izkušenega posameznika novozaposlenemu posamezniku pomeni mentorstvo možnost nadaljevanja uporabe znanj in izkušenj v podjetju, prekvalifikacijo ter s tem ob nadgradnji znanja tudi večjo konkurenčnost podjetja v prihodnosti. Po drugi strani je mentorstvo brezposelni osebi ključnega pomena za pridobivanje znanj in izkušenj s ciljem povečevanja zaposlitvenih možnosti pri aktualnem ali bodočem delodajalcu.

Seveda se ob neupoštevanju pravil igre na površju prikažejo tudi možne slabosti sistema mentorstva. Mentorstvo mladim lahko ob odsotnosti ciljne usmerjenosti in pomanjkljivem spremljanju napredka ter nadgradnje teoretičnega znanja vodi v izkoriščanje poceni delovne sile, celo $v$ trajnejše nadomeščanje delavcev zgolj z mladimi iskalci znanja zaradi zgoraj navedenih vzrokov. Aktivna vloga socialnih partnerjev in korekten pristop $\mathrm{k}$ mentorskim shemam sta pri izogibanju zlorabam izrednega pomena, tudi $\mathrm{z}$ vidika zaupanja $\mathrm{v}$ sistem mentorstva.

Prenos znanja je za sodobno družbo ključnega pomena, najbolj uspešen pa je, če gre za dvosmerni tok, kjer se vsak posameznik zaveda, da lahko svoje znanje, izkušnje, ideje in voljo do znanja preda naprej drugim. Opisani ukrepi mentorstva lahko postanejo konkretna aktivnost v povezovanju generacij. Glede na izkazano uspešnost prenosa znanj in izkušenj v obliki mentorstva je torej primerno, da čim hitreje sistemsko uredimo pripravništvo, kot izhaja iz predloženih dokumentov in pobud, pri tem pa upoštevamo zanimive primere že uveljavljenih dobrih praks drugih držav pri načrtovanju lastnih mentorskih oblik.

\section{LITERATURA IN VIRI:}

Towards a Rich-Job recovery. COM (2012) 173

final. European Commission. Luxembourg:

Office for Official Publications of the European Communities. 
Implementing the Youth Opportunity Initiative: First steps taken. SWD (2012) 98 final. European Commission. Luxembourg: Office for Official Publications of the European Communities.

Quality Framework for Traineeship. SWD (2012) 99 final. European Commission. Luxembourg: Office for Official Publications of the European Communities.

Youth Opportunity Initiative. COM (2011) 933 final. European Commission. Luxembourg: Office for Official Publications of the European Communities.

Draft Joint Employment Report. COM (2011) 815 final. European Commission. Luxembourg: Office for Official Publications of the European Communities.

Youth in Move. COM (2010) 477 final. European Commission. Luxembourg: Office for Official Publications of the European Communities.

Pregled ukrepov za spodbujanje aktivnega staranja (2010). Ljubljana: Ministrstvo za delo, družino in socialne zadeve. Dostopno na:

http:www.mddsz.gov.si/si/zakonodaja_in_dokumenti/pomembni_dokumenti/\#c8070

Zakon o urejanju dela (ZUTD) (2010). Uradni list $R S, 80 / 2010$.

1 COM (2010) 477 final, 15. september 2010.

2 Poročevalka: Emilie Turunen, poslanka Evropskega parlamenta, EP 2009/2221(INI), 14. junij 2010.

3 COM (2011) 933 final, 20. december 2011.

4 Sklepi Sveta 11838/11 »Spodbujanje zaposlovanja mladih za uresničitev ciljev strategije Evropa $2020 \ll ; 17$. junij 2011.

5 COM (2012) 173 final, 18. april 2012.

6 www.qualityinternships.eu. 